\title{
Biplot and Correlation Analysis of 189 Superior F2 Genotypes Chili-Unpad in Indonesia
}

\author{
Ratna Fitry ${ }^{1 *}$, N Rostini, Hersanti ${ }^{2}$, Anas $^{2}$ \\ ${ }^{1}$ Postgraduate Program of Plant Science, Agriculture Faculty, Universitas Padjadjaran \\ ${ }^{1}$ Agriculture Faculty, Universitas Sultan Ageng Tirtayasa \\ ${ }^{2}$ Agriculture Faculty, Universitas Padjadjaran \\ J1. Raya Jatinangor Km 21 Bandung, Indonesia \\ *ratnafitry83@yahoo.co.id
}

\begin{abstract}
This study aimed to examine genotype variations based on biplot analysis and correlation among the superior characters F2 genotype of Chili Unpad in Sumedang. The genetic material evaluated in this study was $187 \mathrm{~F} 2$ genotypes of Chili Unpad which were the result of crossing of local genotypes from crosses of female parent $\mathrm{CFO} 2$ and male parent K15. The experiment was arranged based on a randomized block design, with 3 replications of the parents while the test genotype did not repeat so that 193 units were obtained. Data analysis was performed on fruit surface, fruit bright, fruit shape, ripe fruit color, fruit length, fruit diameter, number of fruit, fruit weight per plant, weight per fruit, and Capsaicin content include Biplot Analysis and Correlation Analysis. The results of the analysis showed that the total diversity that can be explained was $97.8 \%$ superior F2 genotype of chili-Unpad in Sumedang. Fruit spiciness, fruit surface, fruit length, weight per plant, weight per fruit and spiciness have a positive and significant correlation with capsaicin content.
\end{abstract}

Keywords: biplot, correlation, superior F2 chili-Unpad, capsaicin

\section{INTRODUCTION}

Chili pepper (Capsicum annuum L.) is one of the potential horticultural commodities to be developed because it has high economic value in Indonesia [1]. This is due to the spread of extensive production and chili plants can be planted both in the highlands, medians, and in the lowlands, without requiring special agro-climate requirements. Chili pepper is very popular in the market, especially as a food flavoring because of its spicy flavor and the capsaicin content (active substance) [2]. Chili spiciness is caused by the capsaicin compound $\left(\mathrm{C}_{18} \mathrm{H}_{27} \mathrm{NO}_{3}\right)$ in fruit placenta. In general, chili has many nutrients and vitamins, including calories, protein, fat, carbohydrates, calcium, vitamin A, B1, and vitamin $\mathrm{C}[3]$. The chili varieties that are preferred by consumers are high yield, disease resistance, and spicy which guarantees the continuity of production. But chili production in several regions of Indonesia showed that was not optimal. Various factors involved such as weather influences, low seed quality, and attacked by Plant Disrupting Organisms. The assembly of chili varieties has the superior character is the first step in supporting the chili plant breeding program to obtain new varieties as a collection of chili germplasm.

In this study aimed to examine genotype variations based on biplot analysis and correlation. Biplot analysis is used to estimate the grouping of genotypes of various characters. Correlation measures between capsaicin and fruit characters. This method to determine whether there is a relationship between fruit characters and capsaicin content so that it is helpful to improve correlated responses [4]. 


\section{MATERIALS AND METHODS}

The experiment was carried out in 2016-2017 at the field Ciparanje, Jatinagor, Sumedang with altitude $780 \mathrm{~m}$ above sea level. The study was arranged based on a randomized block design without spatial planning on 187 F2 genotypes resulting from local crosses between $\mathrm{CFO} 2$ as female and $\mathrm{K} 15$ as males.

The linear method of randomized block design is as follows:

$Y_{i j}=\mu+t_{i}+r_{j}+\varepsilon_{i j}$

Description :

$\mathrm{Y}_{\mathrm{ij}}=$ response of $\mathrm{i}$-treatment and $\mathrm{j}$-group

$\mu \quad=$ middle population value

$\mathrm{t}_{\mathrm{i}}=$ the addive effect of $\mathrm{i}$-treatment

$r_{j} \quad=$ the addive effect of $j$-test

$\varepsilon_{\mathrm{ij}}=$ the effect of experimental error

Data analysis was performed on fruit surface, fruit bright, fruit shape, ripe fruit color, fruit length, fruit diameter, number of fruit, fruit weight per plant, weight per fruit, and Capsaicin content include Biplot Analysis and Correlation Analysis. Data analysis using the SAS program.

The maximum distance of the center to determine the general character is stated by the Hotelling test approach (Johnson and Wichern, 2014) as follows:

$$
\mathrm{ri}_{ \pm} \sqrt{\frac{p(n-1)}{(n-p)}} \mathrm{F}_{(\alpha, \mathrm{p}, \mathrm{n}-\mathrm{p})} \sqrt{\frac{s^{2} P C_{i}}{n}}
$$

where $r_{i}=$ ellipse radius for PCi, $\mathrm{p}=\mathrm{PC}$ component used, $\mathrm{n}$ $=$ number of lines tested, $\mathrm{F}_{(\alpha, \mathrm{p}, \mathrm{np})}=$ distribution $\mathrm{F}$ at $5 \%$ chance with free degrees $\mathrm{p}$ and n-p, PCi s = variance of PCi score

Character that is in the area in the ellipse, expressed by the formula:

$$
\frac{\left(P C 1_{i}\right)^{2}}{\left(r_{1}\right)^{2}}+\frac{\left(P C 2_{i}\right)^{2}}{\left(r_{2}\right)^{2}}<1
$$

The line group is determined based on the sector area between two lines through $(0,0)$ which is perpendicular to the line connecting the two outer points of the polygon.

\section{RESULTS AND DISCUSSIONS}

The relationship among the genotypes tested can be seen in the biplot graph of the two main components which are divided into four quadrants (Figure 1). Biplot analysis is descriptive with two dimensions that present objects and variables in one graph. Biplot analysis can be used to determine the similarity or relative closeness between test genotypes and the diversity of each variable [5].

Biplot analysis result showed that the total diversity can be explained was $97.8 \%$ superior F2 genotype of chili Unpad in Sumedang. Based on Figure 1, the clones in the same quadrant indicated that the genotype had a close genetic relationship. The distribution of genotypes is seen clustered and overlapping in each quadrant. This showed a high level of similarity among genotypes, while several different quadrant genotypes showed a distant genetic relationship. Biplot results also showed that the genotypes were characterized by a relatively high number of fruits and fruit weights per plant. Visually, the length of a vector is uniqueness that is related to each character observed [6].

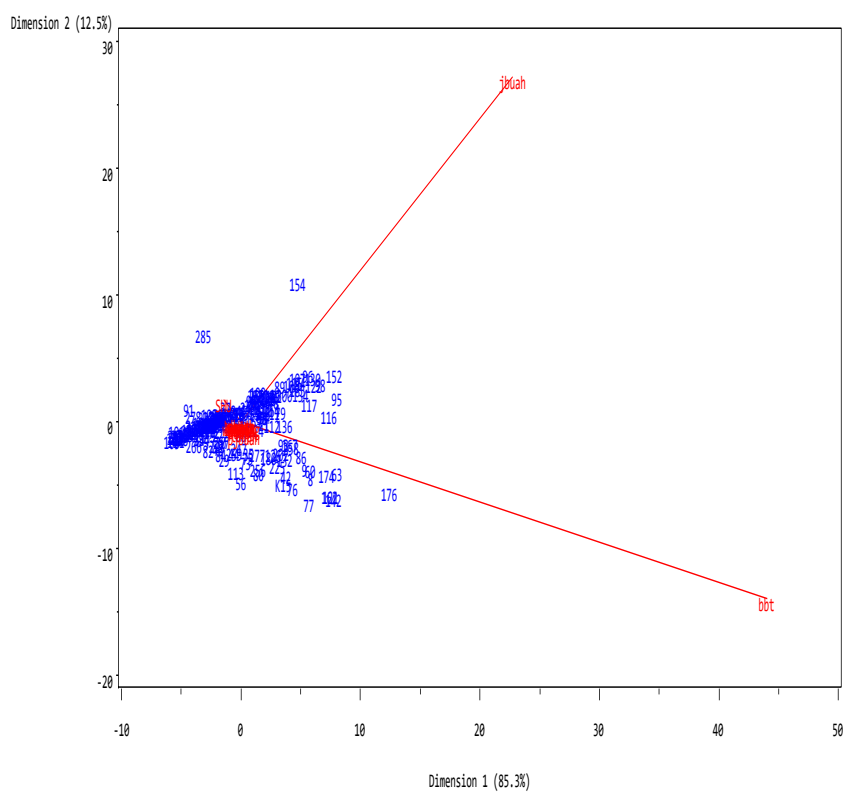

Fig. 1 Biplot of several superior F2 genotypes Chili-Unpad in Sumedang 
From the biplot graph it appears that the genotype cluster spreads to each other. The further location of two objects means the more characteristic values shown by the values of the variables [5]. The diversity of each variable is in the large to small range. The diversity of a variable is known from the vector length of a variable. The longer vector of a variable means the greater diversity of variables [5]. The variable capsaicin $(\mathrm{Y})$, fruit color $(\mathrm{Z} 4)$, fruit length (Z5), fruit diameter (Z6), fruit weight per plant (Z8), and weight per fruit (Z9) have a large variety.

The relationship among characters in chili can be a special and general character at least one character in the line that showed the traits can be characterized in chili. Correlation is a value of the relationship between two variables to determine the level of change in the value of a variable to changes in the value of other variables [7]. Correlation coefficients of various quantitative and qualitative variables on capsaicin levels in 189 chili genotypes of Unpad collections tested in this study are presented in Table 1. The correlation results showed that several characters were very significantly correlated with capsaicin levels. The results of correlation analysis showed that the character of fruit surface, fruit length, fruit diameter, fruit weight per plant, weight per fruit correlated very significantly with capsaicin levels. Then, these fruit characteristics used in the path analysis, because this character correlated with capsaicin levels $(\mathrm{P}>0.05)$ based on the Pearson correlation test.

Table 1. Result of correlation coefficients among fruit characters in F2 chili

\begin{tabular}{|l|c|c|c|c|c|c|c|c|c|c|}
\hline \multicolumn{1}{|c|}{ Traits } & $\mathrm{Z} 1$ & $\mathrm{Z} 2$ & $\mathrm{Z} 3$ & $\mathrm{Z} 4$ & $\mathrm{Z} 5$ & $\mathrm{Z} 6$ & $\mathrm{Z} 7$ & $\mathrm{Z} 8$ & $\mathrm{Z} 9$ & $\mathrm{Y}$ \\
\hline Fruit surface & 1 & $\begin{array}{c}.365 \\
* *\end{array}$ & $\begin{array}{c}.720 \\
* *\end{array}$ & $\begin{array}{c}.355 \\
* *\end{array}$ & $.677^{* *}$ & 0.055 & -0.057 & $.397^{* *}$ & $.647^{* *}$ & $-.233^{* *}$ \\
\hline Fruit bright & & 1 & $\begin{array}{c}.345 \\
* *\end{array}$ & $\begin{array}{c}1.00 \\
0^{* *}\end{array}$ & $.305^{* *}$ & 0.059 & 0.023 & $.208^{* *}$ & $.347^{* *}$ & -0.081 \\
\hline Fruit shape & & & 1 & $\begin{array}{c}.350 \\
* *\end{array}$ & $.949^{* *}$ & 0.048 & -0.09 & $.528^{* *}$ & $.847^{* *}$ & $-.259^{* *}$ \\
\hline
\end{tabular}

\begin{tabular}{|l|l|l|l|l|l|l|l|l|l|l|}
\hline Ripe fruit color & & & & 1 & $.312^{* *}$ & 0.051 & -0.028 & $.208^{* *}$ & $.350^{* *}$ & -0.088 \\
\hline Fruit length & & & & & 1 & 0.044 & -0.085 & $.548^{* *}$ & $.871^{* *}$ & $-.276^{* *}$ \\
\hline Fruit diameter & & & & & & 1 & $.237^{* *}$ & $.227^{* *}$ & 0.096 & $-.186^{*}$ \\
\hline Number of fruit & & & & & & & 1 & $.678^{* *}$ & $-.151^{*}$ & -0.08 \\
\hline $\begin{array}{l}\text { Fruit weight per } \\
\text { plant }\end{array}$ & & & & & & & & 1 & $.525^{* *}$ & $-.210^{* *}$ \\
\hline Weight per fruit & & & & & & & & & 1 & $-.285^{* *}$ \\
\hline Capsaicin content & & & & & & & & & 1 \\
\hline
\end{tabular}

Note: $\quad$ Z1: fruit surface; Z2: fruit bright; Z3: fruit shape; Z4: ripe fruit color; Z5: fruit length; Z6: fruit diameter; Z7: number of fruit; Z8: fruit weight per plant; Z9: weight per fruit; Y: Capsaicin content

Characteristics of Capsaicin Level had a real negative correlation with several other characters. This indicated increase in Capsaicin levels will reduce the appearance of other characters or otherwise. Statistical analysis showed that fruit surface, fruit length, fruit diameter, fruit weight per plant, and fruit weight were negatively correlated. This means that the rougher surface of the fruit, the higher level of capsaicin. So does the fruit length and diameter of the fruit. The shorter fruit and the smaller fruit diameter mean the higher capsaicin level. This is because there is a density of capsaicin found in placenta, fruit flesh, and seeds that make the character of spiciness higher. While, a real positive correlation and no real negative correlation among characters mean that one character will improve another character[8]. The fruit bright and number of fruits were not significantly different from the levels of capsaicin. Thes the higher capsaicin level. This is because there is a density of capsaicin found in placenta, fruit flesh, and seeds that make the character of spiciness higher. While, a real positive correlation and no real negative correlation among characters mean that one character will improve another character [8]. The fruit bright and number of fruits were not significantly different from the levels of capsaicin. These characters cannot be used as selection criteria to get chili 
which has high or low capsaicin. Additional data, the biggest correlation coefficient value in Sumedang was on fruit color with a fruit resistance of 1.000 , this means that fruit color improvements will increase fruit resistance.

High correlation indicates the closeness of the relationship between the observed characters but cannot prove a causal relationship. Path analysis can be used to determine direct and indirect influences [9]. Path analysis was used to determine the direct and indirect effects of capsaicin levels which were then used as information for selection to obtain high-generation of F2 chili [10]. Path diagrams are used to determine the interaction between one character and another character. The results of this analysis will find out the ammount of direct and indirect effects because it is correlated with capsaicin levels (Table 2). The amount of direct and indirect influence provides the effectiveness of the selection of capsaicin levels. There is a relationship between morphological characters and capsaicin levels which are used as morphological character selection criteria to obtain the required character of fruit components.

The results of path analysis showed that there were five characters that provide a direct influence with real coefficients. These characters were fruit surface, fruit length, fruit diameter, fruit weight per plant, and weight per fruit. The biggest total influence was fruit diameter (-0.176), but had the smallest direct effect $(-0.149)$, so the total influence is more indirectly influenced by the fruit surface character $(-0.00293)$ which showed that the character had the greatest influence on the level capsaicin. The other major total effect was fruit weight per plant (-0.216) with a small direct effect (-0.026), so the weight per fruit character gave a fairly high indirect effect. The lowest total effect was on the weight per fruit $(-0.299)$ with direct influence ($0.140)$.
Tabel 2. Direct and indirect effect for the five quantitative characteristics of chili (Capsicum annuum L.).

\begin{tabular}{|c|c|c|c|c|c|c|c|}
\hline \multirow{2}{*}{ Variable } & \multirow{2}{*}{$\begin{array}{l}\text { Direct } \\
\text { influen } \\
\text { ce }\end{array}$} & \multicolumn{5}{|c|}{ Indirect influence } & \multirow{2}{*}{ Total } \\
\hline & & $\mathrm{Z} 1$ & $\mathrm{Z} 5$ & Z6 & $\mathrm{Z8}$ & $\mathrm{Z9}$ & \\
\hline $\begin{array}{l}\text { Fruit } \\
\text { surface }\end{array}$ & -.053 & 0 & -0.076 & $-0,008$ & -0.010 & $\begin{array}{c}- \\
0.091\end{array}$ & -238 \\
\hline $\begin{array}{l}\text { Fruit } \\
\text { length }\end{array}$ & -.112 & -0.035 & 0 & $-0,007$ & -0.014 & $\begin{array}{c}- \\
0.122\end{array}$ & -290 \\
\hline $\begin{array}{l}\text { Fruit } \\
\text { diameter }\end{array}$ & -.149 & $-0,003$ & $-0,005$ & 0 & $-0,006$ & $\begin{array}{c}- \\
0.013\end{array}$ & -.176 \\
\hline $\begin{array}{l}\text { Fruit } \\
\text { weight } \\
\text { per plant }\end{array}$ & -.026 & -0.021 & -0.061 & $-0,034$ & 0 & $\begin{array}{c}- \\
0,074\end{array}$ & -216 \\
\hline $\begin{array}{l}\text { Weight } \\
\text { per fruit }\end{array}$ & -.140 & $-0,034$ & -0.098 & -0.014 & -0.014 & 0 & -299 \\
\hline
\end{tabular}

Note : Z1: fruit surface; Z5: fruit length; Z6: fruit diameter; Z8: fruit weight per plant; Z9: weight per fruit

The path analysis diagram $\mathrm{s}$ used to further clarify the description of path analysis (Figure 2). By combining geometry diagrams and algebraic equations, statistical analysis studied the correlation between variables and the results were easier to understand. Path diagrams are arranged based on the underlying knowledge about causal relationships based on the hypothesis made [11].

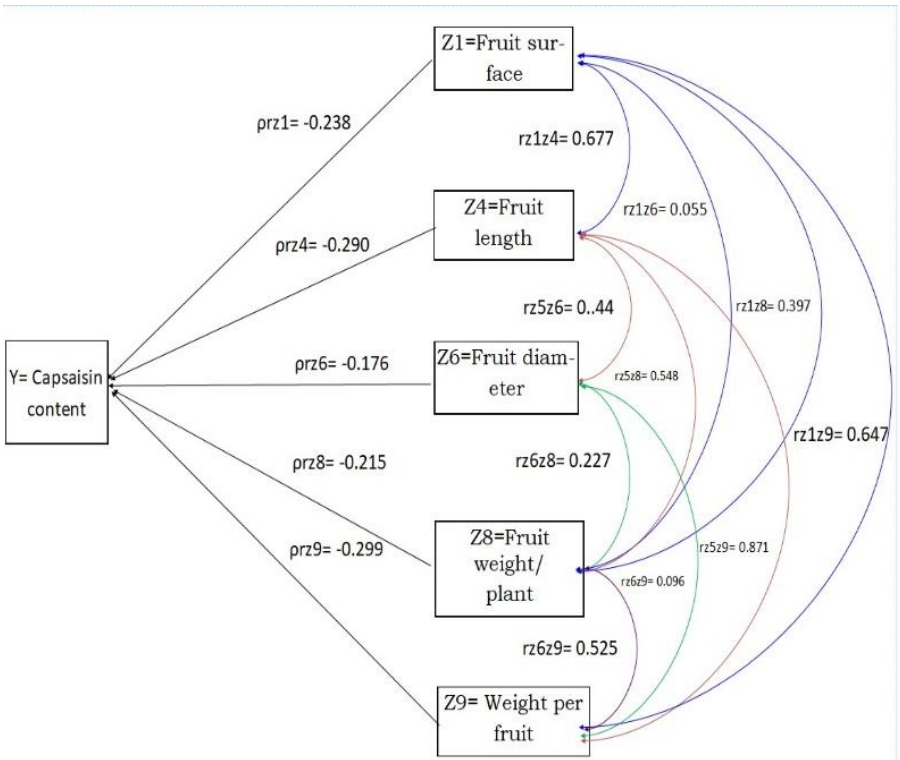

Fig 2. Path analysis quantitative characters in F2-generation of chili 
Efforts to determine character that can be used as effective selection criteria can be seen from the amount of direct influence, the correlation between character, and the difference between the relationship of independent and the direct effect of variables [12]. Characters that have a direct influence on capsaicin levels were fruit surface, fruit length, fruit diameter, fruit weight per plant, and weight per fruit. Morphological characters that had a direct influence can be used as selection criteria to increase spiciness.

\section{CONCLUSION}

Based on the results of the experiment it can be concluded that biplot analysis showed total diversity that can be explained by $97.8 \%$ of superior F2 genotype chili-Unpad tested in Sumedang. Characters of fruit surface, fruit length, fruit diameter, weight per plant, weight per fruit, and spiciness had a significant correlation to capsaicin levels. The fruit bright and number of fruits were not significantly different from the levels of capsaicin.

\section{ACKNOWLEDGMENT}

The authors appreciated to Universitas Padjadjaran for funding the research through Academic Leadership Grant (ALG) 2017-2018

\section{REFERENCES}

[1] Indonesia Statistical Center, "Production of chili, pepper, and red onion in the Indonesia production center," Statistical Center, vol. 71, pp. 1-11, 2014.

[2] P. Hazra, A. Chattopadhyay, K. Karmakar, and S. Dutta, "Modern technology in vegetable production," New Indian Publishing Agency, p. 478, 2011.

[3] S. Agustina, P. Widodo, H. Apriliana, "Phenetic analysis of Capsicum annum L. and Capsicum frutescens L.," Scripta Biologica, vol. 1, no. 1, pp. 117125, 2014.

[4] Falconer and Mackay, Introduction to Quantitative Genetics, England (DE): Longman, 1960.

[5] Sumertajaya, I M., B. Sartono, F. M. Affendi, U. D. Syafitri, and Y.Angraeni, "Variable analysis theory module," Institut Pertanian Bogor, Indonesia, 2003.
[6] M. Munawar, M. Shahbaz, G. Hammad, and M. Yasir, "Correlation and path analysis of grain yield components in exotic maize (Zea mays L.) hybrids," International Journal of Sciences: Basic and Applied Research (IJSBAR), vol. 20, no. 1, pp. 22-27, 2013.

[7] B. Waluyo, D. Saptadi, N. R. Ardiarini, P. Shandila, N. I. Agustina, and C. U. Zanetta, "Selection of chilli pepper lines based on specific traits of agronomic characters using principal component analysis biplot," National Seminar by PERIPI in West Sumatra, October 2018.

[8] Chahal, G.S. and S.S. Gosal, "Principles and procedures of plant breeding: Biotechnological and conventional approaches," Narosa Publishing House, New Delhi, India. 604 p, 2002.

[9] Li, C.C., "The concept of path coefficient and its impact on population genetics," Biometrics, vol. 12, no. 2, pp. 190-210, 1956.

[10] Poerwoko, "Path analysis of several components F5generation rust resistant soybean genotypes," Universitas Jember, Indonesia.

[11] Singh RK, Chaudhary BD, "Biometrical methods in quantitative genetics analysis," New Delhi: Kalyani Publisher, 1985.

[12] Yuniarti, R., Sastrosumarjo, S., Sujiprihati, S., Surahman, M., and Hidayat, S.H., "The selection criteria for assembling Phytopthora capsici L. resistant varieties," Indonesian journal of Agronomy, vol. 38, no. 2, 2010.

[13] Gabriel, K. R., "The biplot graphic display of matrices with application to principal component analysis," Biometrics, vol. 58, pp. 453-467, 1971. 